\title{
IDENTIFIKASI TANDA TANGAN MENGGUNAKAN METODE ZONING DAN SVM (SUPPORT VECTOR MACHINE)
}

\author{
Riska Aristantya*), Imam Santoso, dan Ajub Ajulian Zahra \\ Departemen Teknik Elektro, Universitas Diponegoro \\ J1. Prof. Sudharto, SH, Kampus UNDIP Tembalang, Semarang 50275, Indonesia \\ ${ }^{*}$ E-mail: aristantyar@gmail.com
}

\begin{abstract}
Abstrak
Identifikasi tanda tangan adalah proses untuk mengenali dan menentukan tanda tangan seseorang. Identifikasi tanda tangan termasuk biometik yang menggunakan perilaku alami manusia. Identifikasi tanda tangan dapat digunakan dalam bidang keamanan seperti izin penarikan uang, validasi cek, transaksi kartu kredit dan lainnya. Selama ini identifikasi tanda tangan dilakukan secara manual. Kesulitan dari cara ini, jika tanda tangan yang harus diidentifikasi berjumlah banyak, pemeriksa akan mengalami kelelahan. Untuk mempermudah tersebut perlu dilakukan pengembangan untuk membuat sistem identifikasi tanda tangan yang terkomputerisasi. Pada Penelitian ini dibuat pengembangan identifikasi tanda tangan ini menggunakan metode pencirian zoning dan klasifikasi Support Vector Machine (SVM). Berdasarkan pengujian yang telah dilakukan, pengujian data uji normal menghasilkan akurasi pengenalan sebesar 95,31\%. Pada pengujian data uji dengan gangguan diperoleh akurasi sebesar 21,87\%. Sedangkan pengujian tanda tangan tiruan dihasilkan akurasi sebesar 30\%. Selain pola citra tanda tangan yang telah terdaftar, terdapat juga citra tanda tangan yang tidak terdaftar pada basis data. Akurasi yang didapat pada pengujian ini sebesar $0 \%$.
\end{abstract}

Kata kunci : identifikasi tanda tangan, metode zoning, SVM.

\begin{abstract}
Identification of signatures is the process of identifying and defining a person's signature. Identification of signatures including biometics that use natural human behavior. Identification of signatures can be used in security areas such as money withdrawal permits, check validation, credit card transactions and more. During this signature identification is done manually. Difficulty in this way, if the signature to be identified is large, the examiner will experience fatigue. To simplify it needs to be developed to create a computerized signature identification system. In this research, the development of this signature identification is done using the method of zoning and Support Vector Machine (SVM) classification. Based on the tests that have been done, normal test data test resulted in recognition accuracy of $95.31 \%$. In testing the test data with disturbance obtained accuracy of $21.87 \%$. While the testing of artificial signatures generated an accuracy of $30 \%$. In addition to the registered signature image pattern, there are also signature images that are not registered in the database. The accuracy obtained in this test is $0 \%$.
\end{abstract}

Keywords: signature identification, zoning method, SVM.

\section{Pendahuluan}

Identifikasi pola tanda tangan termasuk dalam jenis biometrik yang menggunakan metode karakteristik perilaku manusia. Secara umum, untuk mengidentifikasi tanda tangan dilakukan dengan cara manual yaitu mencocokkan antara tanda tangan pada waktu transaksi dengan tanda tangan sebelumnya yang sudah sah dengan menggunakan mata. Cara manual memiliki kelemahan jika jumlah pola tanda tangan yang harus dicocokkan dalam suatu waktu berjumlah banyak, pemeriksa akan mengalami kelelahan sehingga hasil pencocokkan kurang maksimal karena penulisan tanda tangan seseorang akan mengalami perubahan seiring waktu. Perubahan menjadikan tanda tangan seseorang memiliki bentuk yang tidak identik. Tanda tangan yang identik adalah tanda tangan yang memiliki pola yang sama dan sebangun, hal ini mengenai posisi, ukuran maupun tekanan saat tanda tangan dilakukan. Perubahan tanda tangan seseorang dipengaruhi oleh waktu, usia, kebiasaan dan keadaan mental seseorang [1]. Oleh karena itu, diperlukan suatu metode yang mampu mempermudah proses identifikasi tanda tangan dengan memanfaatkan teknologi pengolahan citra digital.

Berkaitan dengan identifikasi tanda tangan, banyak penelitian biometrik tanda tangan dengan menggunakan 
berbagai metode. Seperti menggunakan metode pencirian Image Centroid Zone (ICZ) dan Zone Centroid and Zone (ZCZ) [4], menggabungkan metode zoning dan diagonal baased [5], untuk pengenalannya menggunakan metode jaringan syarag tiruan [7], Principal Component Analysis (PCA) [10].

Pada Penelitian ini akan dibahas mengenai analisis dan simulasi sistem identifikasi tanda tangan menggunakan metode pencirian zoning untuk memperolah nilai karakteristik dari citra tanda tangan. Kemudian nilai karakteristik akan diklasifikasi menggunakan metode SVM.

\section{Metode}

\subsection{Perancangan Sistem}

Sistem yang dirancang adalah perangkat lunak guna mengenali tanda tangan terdiri dari tahap pelatihan dan pengujian.

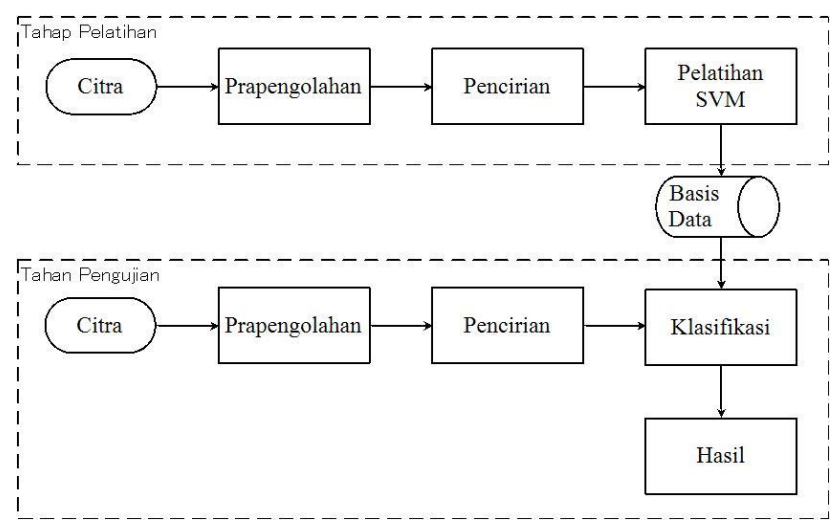

Gambar 1. Diagram blok sistem identifikasi tanda tangan

Gambar 1 menunjukkan bahwa pada tahap pelatihan terdiri dari beberapa proses yaitu prapengolahan, pencirian menggunakan metode zoning, dan proses pelatihan SVM. Dari proses pelatihan SVM akan diperoleh basis data yang akan digunakan pada proses klasifikasi.

Pada tahap pengujian citra akan mengalami proses prapengolahan dan proses pencirian. Nilai fitur yang didapat akan dibandingkan dengan basis data.

\subsection{Metode Pencirian Zoning}

Pencirian atau feature extraction merupakan proses yang mana tiap-tiap sampel sinyal akan diubah menjadi vektorvektor data. Metode yang akan digunakan pada proses pencirian dalam identifikasi tanda tangan ini adalah metode zoning. Zoning memiliki beberapa keunggulan dibandingkan dengan metode lainnya, antara lain metode pencirian yang sederhana, kompleksitas yang rendah dan memiliki perhitungan yang cepat dalam mengekstraksi ciri suatu karakter.

Menghitung metode zoning dapat dibagi menjadi 3 proses:

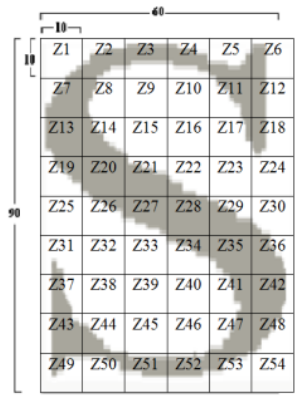

Gambar 2. Pembagian zona menjadi 6 kolom dan 9 baris

1. Menghitung jumlah piksel hitam setiap zona. Misal dari Gambar 2 didapatkan nilai piksel hitam tiap zona seperti Tabel 1 .

Tabel 1. Jumlah piksel hitam setiap zona

$\begin{array}{llllll}Z Z 1=15 & Z 2=56 & Z 3=41 & Z 4=45 & Z 5=55 & Z 6=30 \\ Z 7=86 & Z 8=10 & Z 9=0 & Z 10=0 & Z 11=46 & Z 12=30 \\ Z 13=98 & Z 14=44 & Z 15=0 & Z 16=0 & Z 17=6 & Z 18=29 \\ Z 19=47 & Z 20=100 & Z 21=65 & Z 22=11 & Z 23=0 & Z 24=0 \\ Z 25=0 & Z 26=33 & Z 27=88 & Z 28=98 & Z 29=54 & Z 30=3 \\ Z 31=2 & Z 32=0 & Z 33=3 & Z 34=47 & Z 35=98 & Z 36=57 \\ Z 37=35 & Z 38=0 & Z 39=0 & Z 40=0 & Z 41=47 & Z 42=89 \\ Z 43=76 & Z 44=8 & Z 45=0 & Z 46=0 & Z 47=42 & Z 48=56 \\ Z 49=45 & Z 50=43 & Z 51=38 & Z 52=46 & Z 53=51 & Z 54=5\end{array}$

2. Menentukan zona yang memiliki jumlah piksel paling tinggi.

Dari Tabel 1 didapat nilai piksel maksimum $Z_{\text {tertinggi }}=100$

3. Menghitung nilai fitur setiap zona dari.

Nilai fitur $Z_{n}=Z_{n} / Z_{\text {tertinggi }}$

$1 \leq n \leq 54$

Menggunakan persamaan 1, sehingga didapatkan nilai fitur pada Tabel 2.

Tabel 2. Nilai fitur tiap zona

\begin{tabular}{llllll}
\hline$Z 1=0.15$ & $Z 2=0.56$ & $Z 3=0.41$ & $Z 4=0.45$ & $Z 5=0.55$ & $Z 6=0.3$ \\
$Z 7=0.86$ & $Z 8=0.1$ & $Z 9=0$ & $Z 10=0$ & $Z 11=0.46$ & $Z 12=0.3$ \\
$Z 13=0.98$ & $Z 14=0.44$ & $Z 15=0$ & $Z 16=0$ & $Z 17=0.06$ & $Z 18=0.29$ \\
$Z 19=0.47$ & $Z 20=1$ & $Z 21=0.65$ & $Z 22=0.11$ & $Z 23=0$ & $Z 24=0$ \\
$Z 25=0$ & $Z 26=0.33$ & $Z 27=0.88$ & $Z 28=0.98$ & $Z 29=0.54$ & $Z 30=0.03$ \\
$Z 31=0.02$ & $Z 32=0$ & $Z 33=0.03$ & $Z 34=0.47$ & $Z 35=0.98$ & $Z 36=0.57$ \\
$Z 37=0.35$ & $Z 38=0$ & $Z 39=0$ & $Z 40=0$ & $Z 41=0.47$ & $Z 42=0.89$ \\
$Z 43=0.76$ & $Z 44=0.08$ & $Z 45=0$ & $Z 46=0$ & $Z 47=0.42$ & $Z 48=0.56$ \\
$Z 49=0.45$ & $Z 50=0.43$ & $Z 51=0.38$ & $Z 52=0.46$ & $Z 53=0.51$ & $Z 54=0.05$ \\
\hline
\end{tabular}

\subsection{Support Vector Machine (SVM)}

SVM adalah suatu sistem pembelajaran yang menggunakan ruang hipotesis dari suatu fungsi linear dalam suatu ruang dimensi berfitur tinggi yang dikembangkan oleh Boser, Vapnik, dan pertama kali dipresentasikan pada tahun 1992 di Annual Workshop on 
Computational Learning Theory. SVM bertujuan menemukan hyperplane terbaik yang memisahkan dua buah kelas pada input space. Hyperplane pemisah terbaik antara kedua kelas dapat diukur dengan mengukur margin hyperplane yang diperoleh dari mengukur margin yang maksimal antara ruang input non-linear dengan ruang ciri menggunakan kaidah kernel.

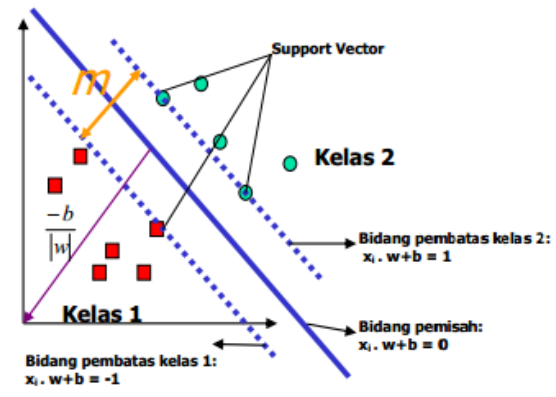

\section{Gambar 3. Ilustrasi Linearly Separable Data}

Pada Gambar 3 dua kelas dipisahkan oleh sepasang bidang pembatas yang sejajar. Bidang pembatas pertama membatasi kelas pertama (kotak) sedangkan pembatas kedua membatasi kelas kedua (lingkaran), sehingga pattern $x_{i}$ yang termasuk kelas 1 (sampel negatif) mempengaruhi pertidaksamaan:

$$
x_{i} \cdot w+b \leq-1
$$

Sedangkan pattern yang termasuk dalam kelas 2 (sampel positif) dapat dirumuskan menggunakan pertidaksamaan:

$$
\begin{array}{ll} 
& x_{i} \cdot w+b \geq+1 \\
w & : \text { bobot } \\
x & : \text { label kelas } \\
b & : \text { bias }
\end{array}
$$

Diasumsikan kedua kelas -1 dan +1 dapat terpisah sempurna oleh hyperplane. Hyperplane pemisah terbaik antara kedua kelas dapat ditemukan dengan mengukur margin hyperplane tersebut dan mencari titik maksimalnya. Margin merupakan jarak antara hyperplane tersebut dengan pattern terdekat dari masing-masing kelas. Nilai margin (jarak) antara hyperplane berdasarkan rumus jarak ke titik pusat dapat didefinisikan:

$$
\frac{1-b-(-1-b)}{w}=\frac{2}{|w|}
$$

Dengan mengalikan $b$ dan $w$ dengan sebuah konstanta, akan menghasilkan nilai margin yang dikalikan dengan konstanta yang sama. SVM meggunakan konsep margin yang didefinisikan sebagai jarak terdekat antara decision boundary dengan sembarang data training, dengan memaksimumkan nilai margin maka akan didapat suatu decision boundary tertentu. Margin terbesar didapat dengan memaksimalkan nilai jarak antara hyperplane dan titik terdekatnya yaitu $\frac{1}{|w|}$. Maka pencarian hyperplane terbaik dengan nilai margin terbesar dapat dirumuskan menjadi masalah optimasi konstrain yaitu mencari titik minimal persamaan (5) dengan memperhatikan constraint persamaan (6).

$$
\begin{array}{lc} 
& \min \frac{1}{2}|w|^{2} \\
& y_{i}\left(x_{i} \cdot w+b\right)-1 \geq 0 \\
& f\left(x_{d}\right)=\sum_{i=1}^{n s} \alpha_{i} y_{i} x_{i} x_{d}+b \\
x_{i} & \text { : support vector } \\
x_{d} & \text { : data yang akan diklasifikasi } \\
n s & \text { : jumlah support vector }
\end{array}
$$

Selain dapat menyelesaikan permasalahan linear. SVM dirancang dapat menyelesaikan permasalahan non-linear dengan memetakan permasalahan tersebut ke dalam ruang ciri berdimensi lebih tinggi kemudian diterapkan klasifikasi linear dalam ruang tersebut.

\section{Hasil dan Analisa}

Pengujian dilakukan terhadap 16 individu yang masingmasing individu terdiri dari 12 citra latih dan 4 citra uji. Pengujian dilakukan untuk mengetahui keberhasilan program dalam mengenal tanda tangan sebagai individu yang benar pada identifikasi tanda tangan. Setelah file citra yang akan dilatih maupun citra yang akan diuji dipilih, citra akan mengalami proses prapengolahan seperti Gambar 4.
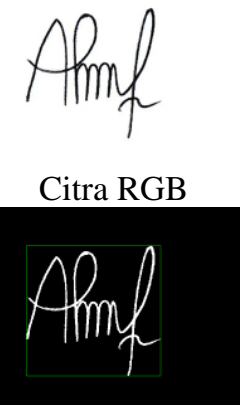

Bounding box
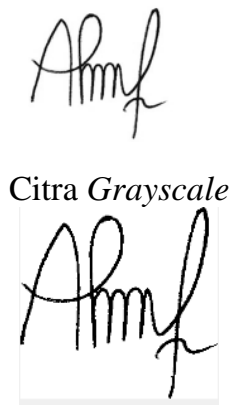

Crop

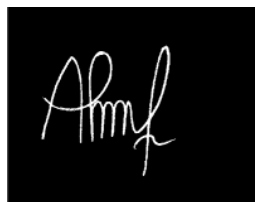

Citra Biner

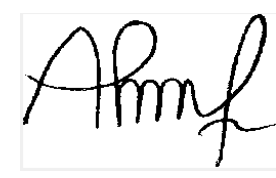

Resize $150 \times 90$

\section{Gambar 4. Proses prapengolahan citra tanda tangan}

Citra uji merupakan citra RGB, untuk mempermudah proses selanjutnya citra akan dikonversi menjadi citra grayscale. Proses selanjutnya merupakan konversi citra menjadi citra biner. Citra biner terdiri dari dua bit yaitu 1 dan 0 . Proses selanjutnya adalah bounding box, proses ini akan menentukan rangkaian piksel yang menjadi batas antara objek dan latar belakang. Kemudian citra akan dipotong dan hanya menyisakan bagian yang dianggap sebagai objek tanda tangan saja. Kemudian citra akan disamakan ukurannya menjadi 150x90 piksel.

Pengujian yang dilakukan dibagi menjadi lima percobaan, yaitu:

1. Pengujian dengan data uji normal yaitu pengujian yang bertujuan untuk mencari akurasi pengenalan dari 64 data citra yang tidak dilatihkan. 


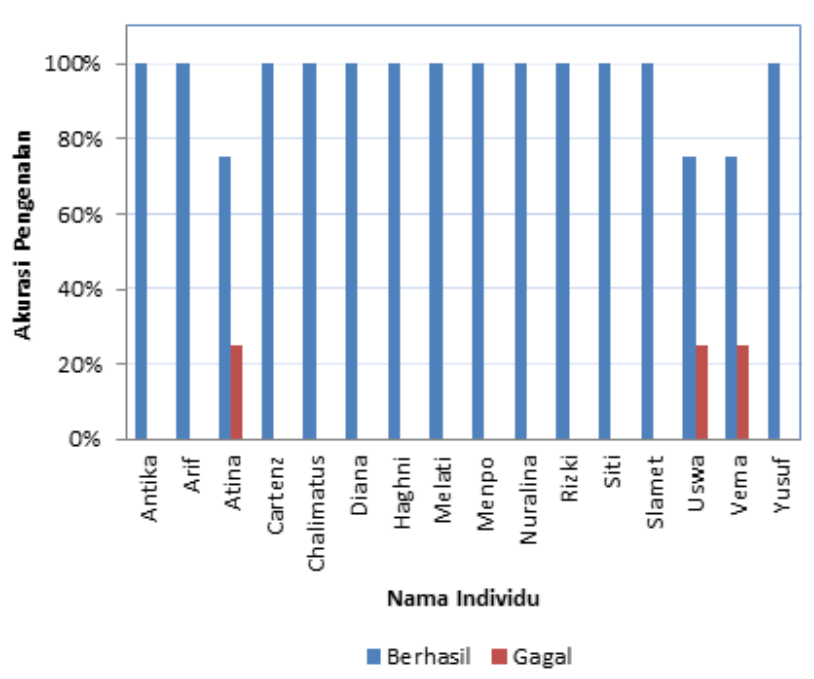

Gambar 5. Grafik pengujian data uji

2. Pengujian data uji dengan gangguan. Pengujian ini bertujuan untuk menguji apakah metode yang digunakan tahan terhadap gangguan. Gangguan yang digunakan adalah gangguan salt\&pepper dengan kerapatan 0,05 .

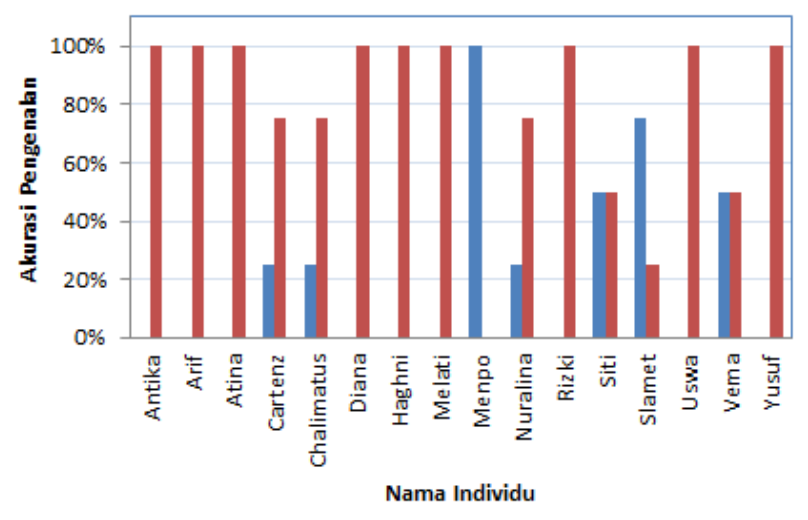

- Uji Gangguan Berhasil Dikenali = Uji Gangguan Gagal Dikenali

Gambar 6. Grafik pengujian data uji normal dan data uji gangguan

3. Pengujian citra tanda tangan tiruan adalah pengujian menggunakan tiruan pola citra tanda tangan yang terdapat dalam basis data. Tiruan pola tanda tangan responden yang berada dalam basis data masingmasing 5 citra, jadi total 80 citra tanda tangan yang diujikan pada percobaan ini. Sebanyak 24 citra tanda tangan dikenali dengan benar, dan akurasi yang didapat sebesar $30 \%$.

4. Pengujian menggunakan citra pola tanda tangan yang tidak terdapat pada basis data. Pada pengujian ini, semua citra dikenali sebagai nama yang terdapat pada basis data. Pengujian ini menggunakan 20 citra data. Dan semua data dikenali salah dan akurasinya sebesar $0 \%$.

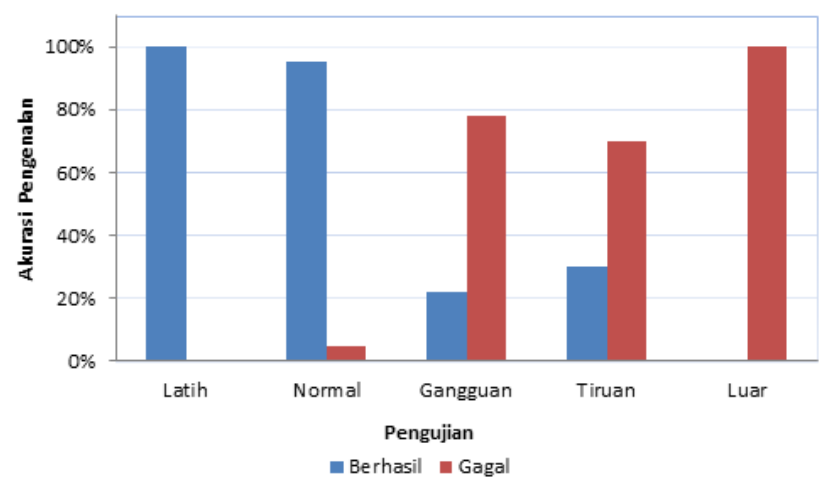

Gambar 7. Grafik akurasi variasi pengujian.

Pada Gambar 7 dapat dilihat bahwa pengujian menggunakan citra latih memiliki akurasi yang sempurna yaitu $100 \%$. Hal ini disebabkan karena citra latih yang diujikan sama dengan citra yang dilatihkan. Pengujian citra uji merupakan pengujian menggunakan citra yang tidak dilatihkan dari orang yang berada dalam basis data. Untuk pengujian data uji memiliki nilai akurasi yang baik yaitu sebesar 95,31\%. Untuk pengujian menggunakan gangguan citra yang digunakan merupakan citra uji yang ditambahkan gangguan salt\&pepper dengan kerapatan 0,05. Metode zoning kurang cocok jika citra yang digunakan terdapat gangguan karene metode zoning akan mencari nilai rata-rata piksel hitam setiap zona. Karena gangguan yang ditambahkan dianggap sebagai bagian tanda tangan sehingga nilai fitur yang dihasilkan berbeda dengan basis data. Akurasi pengenalan yang didapat dari pegujian menggunakan gangguan sebesar $21,87 \%$. Pengujian citra ditiru merupakan pengujian menggunakan citra pola tanda tangan pada basis data dan telah ditirukan sebelumnya. Akurasi pengujian menggunakan citra tiruan dipengaruhi oleh tingkat kemiripan dengan pola yang berada pada basis data, akurasi keberhasilan pada pengujian citra uji sebesar $30 \%$. Pengujian menggunakan citra luar merupakan pengujian menggunakan pola citra tanda tangan yang tidak terdapat pada basis data. Semua citra dikenali sebagai pola yang terdapat pada basis data, hal ini karena perancangan perangkat lunak yang dibuat tidak menggunakan nilai threshold sehingga dengan pendekatan yang digunakan semua citra akan dianggap sebagai pemilik tanda tangan yang berada pada basis data. Nilai akurasi pada pengujian menggunakan data luar sebesar $0 \%$.

\section{Kesimpulan}

Berdasarkan hasil pengujian yang dilakukan, didapat beberapa point-point yang perlu diperhatikan diantaranya jumlah data yang dilatih berpengaruh pada proses pengenalan. Akurasi pada pengujian normal adalah $95,31 \%$. Akurasi pengenalan yang ditambah dengan 
gangguan sebesar $21,87 \%$, hal ini karena gangguan yang ditambahkan dianggap sebagai bagian tanda tangan. Karena tidak menggunakan nilai threshold pengujian menggunakan pola di luar basis data akan tetap dikenali sebagai bagian dari basis data.

\section{Referensi}

[1] R. Abbas, "A Prototype System for Off-Line Signature Verification Using Multilayered Feedforward Neural," 1994.

[2] O. D. Trier, A. K. Jain, and T. Taxt, "Feature Extraction Methods for Character Recognition," Univ. Oslo, vol. 29, no. 4, pp. 641-662, 1996.

[3] N. Amelia, "Pengenalan Pola Huruf Hijaiyah Menggunakan Support Vector Machine (SVM)," 2016.

[4] S. V Rajashekararadhya, "Efficient Zone Based Feature Extration Algorithm for Handwritten Numeral Recognition of Four Popular South Indian Scripts," J. Theor. Appl. Inf. Technol., vol. 4, no. 12, pp. 11711181, 2008

[5] N. Putra, "Peningkatan Nilai Fitur Jaringan Propagasi Balik Pada Pengenalan Angka Tulisan Tangan Menggunakan Metode Zoning dan Diagonal Based Feature Extraction," Universitas Sumatera Utara, 2012.

[6] I. M. G. Sunarya, "Menggunakan Metode Jaringan Syaraf Tiruan Model Perceptron," Univ. Pendidik. dan Ganesha, vol. 7, no. 1, pp. 700-710, 2013.

[7] A. Jariah, "Pengenalan Pola Tanda Tangan Menggunakan Metode Moment Invariant Dan Jaringan Syaraf Radial Basis Function (RBF) Pengertian Tanda Tangan," Univ. Yogyakarta, pp. 85-92, 2011.

[8] D. K. W. Buana, "Identifikasi tanda-tangan menggunakan jaringan saraf tiruan perambatan-balik (backpropagation)," pp. 1-8.

[9] Zaitun and Warsito, "Sistem Identifikasi dan Pengenalan Pola Citra Tanda-Tangan Menggunakan Sistem Jaringan Saraf Tiruan (Artificial Neural Networks) dengan Metode Backpropagation," vol. 3, no. 2, pp. 93-101, 2015.
[10] Z. B. Fiqhi, R. R. Isnanto, and M. Somantri, "Pengenalan Tanda Tangan Menggunakan Analisis Komponen Utama (Principal Component Analysis PCA ) dan Metode Jaringan Saraf Tiruan,” pp. 1-8, 2013.

[11] A. Wibowo, Wirawan, and Y. K. Suprapto, "Verifikasi dan Identifikasi Tanda Tangan Offline Menggunakan Wavelet dan Learning Vector Quantization," Inst. Teknol. Sepuluh Nop., vol. 5, no. 1, pp. 649-655, 2014.

[12] T. Fotak, P. Koruga, and M. Ba, "Online Handwritten Signature Identication: The Basics," 2011.

[13] "Kumpulan Tandatangan Tokoh Dunia," 2012. [Online]. Available: https://mynetsuite.wordpress. com/2012/07/17/kumpulan-tandatangan/.

[14] R. C. Gonzalez and R. E. Woods, Digital Image Processing (3rd ed), Third edit. Upper Saddle River, N. J.: Prentice Hall, 2008.

[15] "Representasi Citra Digital," 2015. [Online]. Available: https://putuadisusanta.wordpress.com/ 2015/07/17/representasi-citra-digital/

[16] "What is The Difference Between A Black and White and Grayscale Image?" 2016.

[17] J. Pradeep, E. Srinivasan, and S. Himavathi, "Diagonal Based Feature Extraction for Handwritten Alphabets Recognition System Using Neural Network," Int. J. Sci. Inf. Technol., vol. 3, no. 1, pp. 27-38, 2011.

[18] O. P. Sharma, M. K. Ghose, and K. B. Shah, "An Improved Zone Based Hybrid Feature Extraction Model for Handwritten Alphabets Recognition Using Euler Number," Int. J. Soft Comput. Eng. , vol. 2, no. 2, pp. 504-508, 2012.

[19] I. Mulia, "Pengenalan Aksara Sunda Menggunakan Ekstraksi Ciri Zoning Dan Klasifikasi Support Vector Machine," 2012.

[20] A. S. Nugroho, A. B. Witarto, and D. Handoko, "Support Vector Machine," 2003.

[21] E. Prasetyo, Data Mining Mengolah Data Menjadi Informasi Menggunakan MATLAB. Yogyakarta: Andi Publisher, 2014.

[22] K. Sembiring, "Penerapan Teknik Support Vector Machine Untuk Pendeteksian Intrusi pada Jaringan," in Institut Teknologi Bandung, 2007, p. II-1.

[23] R. Munir, "Citra Biner," in Pengolahan Citra Digital Dengan Pendekatan Algoritmik, Bandung: Informatika, 2004, pp. 167-182. 